bilateral destruction of the medial and lateral septal nuclei was $88 \%$ and $78 \%$, respectively. No Ss received less than a $99 \%$ complete lesion in the anterior one-third of both the medial and lateral septal nuclei; more posterior sparing of these nuclei was generally found. However, the lesion procedures removed $97 \%$ of both nuclei in one $S$.

In some $\mathrm{Ss}$, incidental bilateral damage was found in the anterior portions of the lateral preoptic area, anterior portion of the diagonal band of Broca, and anterior portion of the lateral parolfactory area (nucleus accumbens septi). Extensive damage to the anterior cingulate cortex and corpus callosum was found in one S. Slight damage to the ventricular wall of the caudateputamen may have occurred in some animals. ${ }^{4}$

\section{DISCUSSION}

We have no explanation of the behavior of the two septals which failed to make an intromission on the first postoperative test. Examination of the lesions failed to suggest any anatomical basis for the performance of these two animals, though it is possible that a transient edema may have been a contributing factor. The females used with these two Ss gave positive indications of behavioral estrus both before and after the tests. During the unsuccessful test sessions, both animals were active and each followed the female and engaged in considerable anogenital sniffing. Neither male showed any signs of aggression toward, or fear of, the female. In fact, although septals were still scoring substantially higher than controls on the King scale (King, 1958) at the time the postoperative sex tests were given, we saw no sign of exaggerated social response to the estrus females on the part of any of the septal males.

Although septal lesions appear to alter other classes of social behavior in rodents (e.g., Bunnell et al, 1965, 1966b; Goodman et al, 1967) they do not have any appreciable effect on sexual behavior in the male laboratory rat as assessed under the present conditions. It appears that the changes in sexual behavior produced by insult to other parts of the limbic forebrain are independent of the integrity of the septal region lesioned in this study. Whether this will be true for species other than the rat awaits further study.

\section{REFERENCES}

BEACH, F. A., \& JORDAN, L. Sexual exhaustion and recovery in the male rat. Quarterly Joumal of Experimental Psychology, 1956, 7, 121-133.

BERMANT, G., GLICKMAN, S. E.. \& DAVIDSON, J. M. Effects of limbic lesions on copulatory behavior of male rats. Joumal of Comparative \& Physiological Psychology, 1968, 65, 118-125.

BUNNELL, B. N., SODETZ, F. J., \& SHALLOWAY, D. I. The effects of septal and amygdaloid lesions on aggressiveness and social dominance in the hamster. Paper read at the

Table 1

Mean Scores on EF and all First Series Measures and Corresponding Values of $\mathrm{f}$ for Kruskal-Wallis One-Way Analyses of Variance of Preoperative-Post Operative Shift Scores for Septal, Control Operate and Normal Control Rats

\begin{tabular}{|c|c|c|c|c|c|c|c|}
\hline \multirow[b]{2}{*}{ Measure } & \multicolumn{2}{|c|}{ Septal } & \multicolumn{2}{|c|}{ Sham } & \multicolumn{2}{|c|}{ Control } & \multirow[b]{2}{*}{$\mathrm{H}^{*}$} \\
\hline & Preop & Postop & Preop & Postop & Preop & Postop & \\
\hline ML & 41.2 & 61.0 & 125.6 & 59.6 & 13.4 & 9.9 & 1.31 \\
\hline IL & 123.0 & 128.6 & 193.4 & 65.4 & 25.2 & 41.2 & 1.39 \\
\hline $\mathrm{EL}_{1}$ & 388.0 & 464.8 & 430.4 & 340.2 & 430.0 & 299.9 & 2.31 \\
\hline$I F_{1}$ & 8.8 & 9.2 & 10.5 & 10.7 & 10.1 & 7.6 & 5.29 \\
\hline$M F_{1}$ & 3.6 & 8.9 & 6.2 & 3.3 & 5.1 & 4.8 & 4.02 \\
\hline $\mathrm{MIII}_{1}$ & 39.4 & 52.1 & 38.6 & 35.8 & 43.8 & 40.2 & 1.52 \\
\hline $\mathrm{PEI}_{1}$ & 325.2 & 302.1 & 336.2 & 331.4 & 342.0 & 335.2 & 1.16 \\
\hline $\mathbf{E F}$ & 7.4 & 6.5 & 7.4 & 7.1 & 7.3 & 7.1 & .50 \\
\hline
\end{tabular}

* $H .05$, df $2=5.99$

annual meeting of the Psychonomic Society, Chicago, October 1965.

BUNNELL, B. N., FRIEL, J., \& FLESHER, C. K. The effects of median cortical lesions on the sexual behavior of the male hamster. Joumal of Comparative \& Physiological Psychology, $1966 \mathrm{a}, 61,492-495$.

BUNNELL, B. N., BEMPORAD, J. R., \& FLESHER, C. K. Septal forebrain lesions and social dominance behavior in the hooded rat. Psychonomic Science, 1966b, 6, 207-208.

DEWSBURY, D. A., GOODMAN, E. D., SALIS, P. J., \& BUNNELL, B. N. Effects of hippocampal lesions on the copulatory behavior of male rats. Physiology \& Behavior, 1968, 3, 651-656.

GOODMAN, E. D., JANSEN, P. A., \& BUNNELL, B. N. Four limbic lesions and maternal behavior in female hamsters. Paper delivered at Psychonomic Society meeting, 1967.

HEIMER, H., \& LARSSON, K. Impairment of mating behavior in male rats following lesions in the preoptic-anterior hypothalamic continuum. Brain Research, 1967, 3, 248-263. KING, F. A. Effects of septal and amygdaloid lesions on emotional behavior and conditioned avoidance responses in the rat. Joumal of Nervous \& Mental Disease, 1958, 126, 67-68.
LARSSON, K. Mating behavior in male rats after cerebral cortex ablations: I. Effects of lesions in the dorsolateral and the median cortex. Joumal of Experimental Zoology, 1962, 151, 167-176.

MICHAL, E. K. The effects of lesions in the limbic system on courtship and mating behavior of male rats. Unpublished doctoral dissertation, University of Illinois, 1965.

MacLEAN, P. D., \& PLOOG, D. W. Cerebral representation of penile erection. Journal of Neurophysiology, 1962, 25, 29-55.

SIEGEL, S. Non-parametric statistics for the behavioral sciences. New York: McGraw-Hill, 1956.

\section{NOTES}

1. This research was supported by Grants GB-6590 and GB-4604 from the National Science Foundation and Research Fellowship 1-F2-MH 37, 424-01 from the National Institute of Mental Health.

2. Present address: Department of Psychology, Emory University, Atlanta, Ga. 30322.

3. Present address: Department of Psychology, University of Georgia, Athens, Ga. 30601.

4. Histological reconstructions may be obtained from the first author.

\title{
Drinking following carbachol stimulation of hippocampal formation or lateral ventricies
}

\section{DAMON MOUNTFORD, The University of Kansas, Lawrence, Kans. 66044}

Direct application of carbachol to the hippocampal formation of rats produced larger increases in drinking than did such applications to the adjacent lateral ventricles. This evidence appears to contradict the hypothesis that drinking following carbachol stimulation of the limbic system results from diffusion of the carbachol to active sites in or near the lateral ventricles.

Direct application of carbachol to a number of central nervous system sites, particularly in the limbic system, elicits drinking behavior (Grossman, 1960, 1964a, b; Fisher \& Coury, 1962; Coury, 1967). Since many of these sites lay near the midline, it was suggested that carbachol may diffuse from the limbic system into the ventricles where it may then act to elicit drinking (Routtenberg, 1967). Some substances, e.g., dopamine, diffuse rapidly from their site of application and, in some cases, concentrate in and around the ventricles (Routtenberg et al, 1968).

Fisher \& Levitt (1967) reported that sites where carbachol elicits drinking lie, in many cases, further from the ventricles than 
inactive sites, and that carbachol injected directly into the posterior horns of the lateral ven tricles produced less drinking than limbic system injections. The occurrence of catatonia and bizarre behavior following ventricular stimulation may have interfered with drinking. It is not clear whether the catatonia and bizarre behavior are the result of carbachol stimulation of any ventricular site, or only of stimulation of the posterior horns of the lateral ventricles.

The objective of the present study was to apply carbachol to the lateral ventricles immediately adjacent to the "active" limbic system tissue. If such applications produce significantly less drinking than do applications to limbic system tissue, then it would seem reasonable to conclude that the limbic system, and not the ventricles, contains the active sites.

\section{METHOD}

A concentric double cannula was permanently implanted in each hippocampal formation (HPC) of 12 male hooded rats (de Groot atlas coordinates: $\mathrm{A}=\mathbf{3 . 0}$; $\mathrm{H}=2.5 ; \mathrm{L}=2.5$ ) and in each lateral ventricle (LV) of five $\mathrm{Ss}(\mathrm{A}=5.0 ; \mathrm{H}=3.0$; $\mathbf{L}=2.5$ ). Electrically insulated double cannulae attached to a socket for taking electrical recordings were implanted in HPC in three Ss. The operative procedures followed Grossman (1960).

Carbachol stimulation (about 1.0 microgram) consisted of removing the inner cannula, cleaning it and tapping crystalline carbachol into its tip, and then returning the inner cannula to the implant site. Control stimulation procedures were identical except no drug was used. Electrical recordings were taken with a Grass Model 7 Polygraph.

Experimentation began 3 weeks after operations. All Ss had free access to food (Purina Rat Lab Chow) and water $24 \mathrm{~h}$ daily. Daily $1-h$ control tests of food and water intake were given in the home cages until stable baselines of intake were established. Carbachol was administered the next day followed by 3 additional days of control tests. "Difference scores" were computed as intake on the carbachol tests minus average intake on the three immediately preceding control tests.

At the end of the experiment, each rat was given $50 \mathrm{mg}$ of Nembutal i.p. and was perfused with $0.9 \%$ saline followed by $10 \%$ Formalin. Frozen sections of 50 -microns thickness were cut from each brain in the region of the implant tip, affixed to slides with albumin, and stained with cresyl violet.

\section{RESULTS}

All intended HPC placements lay within the HPC. Most lay in the middle region of HPC at or near sections 3.0 and 3.4 (de Groot, 1959). Six cannulae tips lay deeper in HPC near the border between HPC

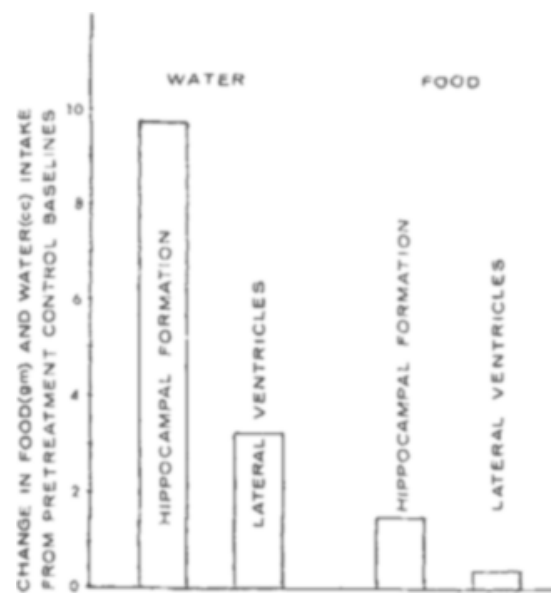

Fig. 1. Change in food and water intake from pretreatment control baselines following carbachol stimulation of hippocampal formation or lateral ventricles in rats satiated on food and water.

and thalamus. Only 3 of the 24 cannulae tip were within $1 \mathrm{~mm}$ of LV. Of the LV implants, seven lay within LV and the other three were within $1 \mathrm{~mm}$ of $\mathrm{LV}$, one in the corpus callosum and two in the caudate nucleus.

As shown in Fig. 1, water intake appears to increase following applications of carbachol to either HPC or LV. The increase in water intake $(\mathrm{av}=9.71 \mathrm{cc})$ following carbachol stimulation of HPC was statistically significant $(t=4.95 ; \quad d f=11$; $\mathrm{p}<.001)$. The increase in water intake $(\mathrm{av}=3.20 \mathrm{cc})$ after stimulation of $\mathrm{LV}$ was not statistically significant $(\mathrm{t}=2.67 ; \mathrm{df}=4$; $p>.05)$. The increase in water intake following carbachol stimulation of HPC was significantly greater than after stimulation of $\operatorname{LV}(\mathrm{t}=2.54 ; \mathrm{df}=15 ; \mathrm{p}<.05)$.

As shown in Fig. 1, the effects of carbachol on food intake were in the same direction as those on water intake but smaller in amount. In no instance was the change in food intake statistically significant (p> 05).

Motor seizures and a catatonic-like state were observed after carbachol stimulation of HPC. This behavior was consistently correlated with the electrical seizure activity recorded from HPC after carbachol. Drinking typically did not occur when such behavior was being emitted. Control tests revealed no electrical or behavioral abnormalities in the same Ss. Carbachol stimulation of LV produced no such motor seizures or catatonia.

\section{DISCUSSION}

The results obtained in this study appear contradictory to Routtenberg's (1967) hypothesis that drinking observed following carbachol stimulation of the limbic system may be a result of diffusion of the carbachol to an "active" site in or near the ventricles of the brain. Carbachol stimulation of HPC in the present study produced significantly larger increases in drinking than stimulation of LV. If carbachol was diffusing to an alternative site of action, that site was probably not LV. In addition, diffusion from LV to another limbic site would appear anatomically more feasible than diffusion from HPC to such an alternative site. It thus appears probable that the increased drinking observed in the present study resulted from an action of carbachol on HPC and not on LV.

The catatonia and bizarre behavior observed by Fisher \& Levitt (1967) after carbachol stimulation of the posterior horns of the LV were not seen in the present study. This difference is presumably due to the more anterior placement of carbachol.

Electrical recordings from HPC indicated that little drinking occurred during periods of HPC electrical seizure activity. The motor seizures and catatonia observed during HPC seizure activity appear to interfere with drinking. These results are consistent with a prior report that drinking may occur following carbachol stimulation of HPC even when clectrical seizure activity does not occur (MacPhail, 1968).

\section{REFERENCES}

COURY, J. N. Neural correlates of food and water intake in the rat. Science, 1967, 156 , 1763-1765.

FISHER, A. E., \& COURY, J. N. Cholinergic tracing of a central neural circuit underlying the thirst drive. Science, 1962, 138, 691-693.

FISHER, A. E., \& LEVITT, R. A. Letter. Answer to Routtenberg. Science, 1967, 157, 839-841.

de GROOT, J. The rat forebrain in stereotaxic coordinates. Transactions of the Royal Netherlands Academy of Science, 1959, 52, 1-40.

GROSSMAN, S. P. Eating and drinking elicited by direct adrenergic or cholinergic stimulation of hypothalamus. Science, 1960, 132, 301-302.

GROSSMAN, S. P. Behavioral effects of chemical stimulation of the ventral amygdala. Journal of Comparative \& Physiological Psychology, 1964a, 57, 29-36.

GROSSMAN, S. P. Effect of chemical stimulation of the septal area on motivation. Journal of Comparative \& Physiological Psychology, $19646,58,194-200$.

MacPHAIL, E. M. Effects of intracranial cholinergic stimulation in rats on drinking, EEG, and heart rate. Journal of Comparative \& Physiological Psychology, 1968, 65, 42-49.

ROUTTENBERG, A. Drinking induced by carbachol: Thirst circuit or ventricular modification? Science, 1967, 157, 838-839.

ROUTTENBERG, A., SLADEK, J., \& BONDAREFF, W. Histochemical fluorescence after application of neurochemicals to caudate nucleus and septal area in vivo. Science, 1968 , $161,272-274$.

\section{NOTE}

1. The author wishes to express his thanks to Walter Randall and Stephen S. Fox for their guidance and useful criticism during the course of this experiment. The data reported formed part of a dissertation submitted by the author for the PhD degree at the University of Iowa, Department of Psychology, 1967. 